\title{
Adjuvant chemotherapy in resected lung cancer: Two-year experience in a university hospital
}

\author{
Nicole Bouchard MD FRCP1 , Francis Laberge MD¹, Bruno Raby MD MSc${ }^{1}$, Sylvie Martin MSc ${ }^{1,2}$, \\ Yves Lacasse MD MSc FRCP ${ }^{1,2}$
}

N Bouchard, F Laberge, B Raby, S Martin, Y Lacasse. Adjuvant chemotherapy in resected lung cancer: Two-year experience in a university hospital. Can Respir J $2008 ; 15(5): 270-274$.

BACKGROUND: Randomized trials have confirmed the benefits of adjuvant chemotherapy in improving survival in resected early-stage non-small-cell lung cancer (NSCLC). The extent to which these results have translated into clinical practice is unknown.

OBJECTIVE: To examine the referral pattern of patients with resected lung cancer to adjuvant chemotherapy, and to compare compliance and toxicities with current literature.

METHODS: A retrospective analysis of all patients who underwent a surgical resection for lung cancer at Laval Hospital (Quebec City, Quebec) from March 2004 to January 2006 was conducted.

RESULTS: A total of 258 patients underwent surgery. Seven patients were excluded because of early postoperative death, and two patients were excluded because of incomplete data. Data from 249 patients were analyzed (94\% NSCLC). Fifty per cent were referred to medical oncology for consideration of adjuvant chemotherapy, including 37 of 61 patients with stage II NSCLC. One hundred patients received chemotherapy. No significant difference in age, sex, comorbidities and surgical procedures was observed between those who received chemotherapy and those who did not. Chemotherapy was initiated 47 days (median) after the surgery and consisted mainly of cisplatinvinorelbine $(38 \%)$, cisplatin-etoposide $(22 \%)$ and carboplatinpaclitaxel (20\%). Sixty-six per cent of the patients completed all four cycles. Grade 3 or 4 toxicities consisted mainly of fatigue $(23 \%)$ and cytopenia (40\%). No death was registered; $15 \%$ had to be hospitalized because of adverse effects.

CONCLUSION: Although adjuvant chemotherapy is gaining acceptance in clinical practice, more patients should be referred to medical oncology following surgical resection. Compliance and toxicity are similar to or better than those described in published randomized trials.

Key Words: Adjuvant chemotherapy; Lung cancer; Referral patterns; Treatment compliance; Treatment toxicity

$\mathrm{L}$ ung cancer remains the leading cause of tumour-related Lmortality in North America (1). Surgery alone has long been the standard of care for patients with operable non-smallcell lung cancer (NSCLC) (2). However, five-year survival rates for stages I, II and IIIA are only $57 \%$ to $67 \%$, $38 \%$ to $55 \%$, and $23 \%$, respectively (3). Recurrences mainly occur at extrathoracic sites, suggesting micrometastatic disease at the time of surgery (4).

\section{Une chimiothérapie adjuvante après une résection du cancer du poumon : Une expérience de deux ans dans un hôpital universitaire}

HISTORIQUE : Des essais aléatoires ont confirmé les bienfaits de la
chimiothérapie adjuvante pour améliorer la survie en cas de résection
d'un cancer bronchopulmonaire non à petites cellules (CBPNPC) au
stade précoce. On ne sait pas dans quelle mesure ces résultats sont
appliqués dans la pratique.
OBJECTIF : Examiner le schème d'aiguillage des patients ayant subi la
résection d'un cancer bronchopulmonaire vers une chimiothérapie adju-
vante, et comparer la compliance et la toxicité avec les publications
courantes. MÉTHODOLOGIE : Les auteurs ont procédé à une analyse rétrospective de tous les patients qui ont subi une résection chirurgicale d'un cancer bronchopulmonaire à l'hôpital Laval (de Québec, au Québec), entre mars 2004 et janvier 2006.

RÉSULTATS : Au total, 258 patients se sont fait opérer. Sept patients ont été exclus en raison d'un décès postopératoire précoce, et deux en raison de données incomplètes. Les données des 249 autres patients ont été analysées (94\% CBPNPC). Cinquante pour cent ont été aiguillés en oncologie médicale pour envisager une chimiothérapie adjuvante, y compris 37 des 61 patients atteints de CBPNPC de stade 2. Cent patients ont reçu une chimiothérapie. On n'a observé aucune différence significative de l'âge, du sexe, des comorbidités et des interventions chirurgicales entre les patients qui ont reçu une chimiothérapie et ceux qui n'en ont pas reçu. La chimiothérapie a été entreprise 47 jours (médiane) après l'opération et était surtout constituée de cisplatine-vinorelbine (38\%), de cisplatineétoposide (22\%) et de carboplatine-paclitaxel (20\%). Soixante-six pour cent des patients ont terminé les quatre cycles complets. Les toxicités de grade 3 ou 4 se manifestaient surtout par de la lassitude ( $23 \%$ ) et une cytopénie (40\%). Aucun décès n'a été enregistré; $15 \%$ ont dû être hospitalisés à cause d'effets secondaires.

CONCLUSION : Même si la chimiothérapie adjuvante devient acceptée en pratique clinique, il faudrait aiguiller davantage de patients en oncologie médicale après une résection chirurgicale. La compliance et la toxicité sont similaires ou supérieures à celles décrites dans les essais aléatoires publiés.

Recent randomized trials $(5,6)$ have confirmed the benefits of adjuvant chemotherapy in improving survival in completely resected NSCLC. A recent pooled analysis of the five largest trials indicated that the five-year absolute benefit of adjuvant cisplatin-based chemotherapy was $4.2 \%$ (5), with absolute improvements of up to $15 \%$ in the National Cancer Institute of Canada Clinical Trials Group JBR,10 trial (6). However, given the timing and nature of adjuvant chemotherapy, toxicities are

${ }^{1}$ Clinique d'oncologie ambulatoire; ${ }^{2}$ Centre de recherche, Centre de pneumologie, Hôpital Laval, Institut universitaire de cardiologie et de pneumologie de l'Université Laval, Quebec City, Quebec

Correspondence: Dr Yves Lacasse, Centre de Pneumologie, Hôpital Laval, 2725 Chemin Sainte-Foy, Sainte-Foy, Quebec G1V 4G5.

Telephone 418-656-4747, fax 418-656-4762, e-mail Yves.Lacasse@med.ulaval.ca 
of concern. In these trials, death was attributable to adjuvant chemotherapy in approximately $1 \%$ of treated patients. Chemotherapy caused febrile neutropenia in $7 \%$ to $9 \%$ of patients, while neutropenia emerged in up to $88 \%$. Compliance with postoperative chemotherapy (defined by three or four completed cycles) in these trials was $48 \%$ to $74 \%$.

In addition, patients with limited small-cell lung cancer (SCLC) may benefit from lung resection. Although the role of adjuvant chemotherapy has not been evaluated in prospective randomized trials, patients with SCLC who undergo complete resection are usually given postoperative chemotherapy (7).

The extent to which the results of these studies have translated into clinical practice is unknown. Our objectives were to examine the referral patterns of patients with resected lung cancer to adjuvant chemotherapy, and to compare compliance and toxicities with the current literature.

\section{METHODS}

\section{Patients}

A retrospective analysis of all patients who underwent a surgical resection for lung cancer at Laval Hospital (Quebec City, Quebec) from March 2004 to January 2006 was conducted. From the hospital medical records department, a list of patients who underwent lung resection (Canadian Coding Sourcebook, codes 44.3 [lobectomy] and 44.4 [pneumonectomy]) for lung cancer (International Classification of Diseases, Ninth Edition, code 162) during this period was obtained. Those who had undergone surgery for pulmonary metastases were excluded.

\section{Data extraction}

Sex, age, forced expiratory volume in $1 \mathrm{~s}$, smoking status and major comorbidities (including chronic obstructive pulmonary disease, coronary artery disease, heart failure, chronic renal failure and diabetes) were noted. Chronic obstructive pulmonary disease was further classified according to the Global Initiative for Chronic Obstructive Lung Disease (8). Data related to the surgical procedure, including the surgeon who performed the resection, the date of surgery, the type and completeness of resection, the histological type, the final surgical staging according to the International System for Staging Lung Cancer (3), and the length of stay in hospital were extracted.

Two important dates were considered: June 1, 2004, corresponding to the publication date of the JBR.10 results at the American Society of Clinical Oncology (ASCO) meeting (5), and June 1, 2005, corresponding to the release of the results of the Adjuvant Navelbine International Trialist Association (ANITA) trial at the ASCO meeting (6). Performance status after the surgery was classified according to the five-point Eastern Cooperative Oncology Group scale (9): 0 indicating full activities without any restriction, and 4 indicating complete disability with confinement to bed or chair.

Information on whether the patient was referred to medical oncology by a surgeon, as well as the reason for not referring, was noted. Chemotherapy regimen of those who were offered adjuvant chemotherapy was recorded. For the patients who received chemotherapy at Laval Hospital, the time between surgery and initiation of adjuvant chemotherapy, the number of cycles completed and chemotherapy-related toxicities (including death) were noted. Toxicity was graded according to the common terminology criteria for adverse events (8).

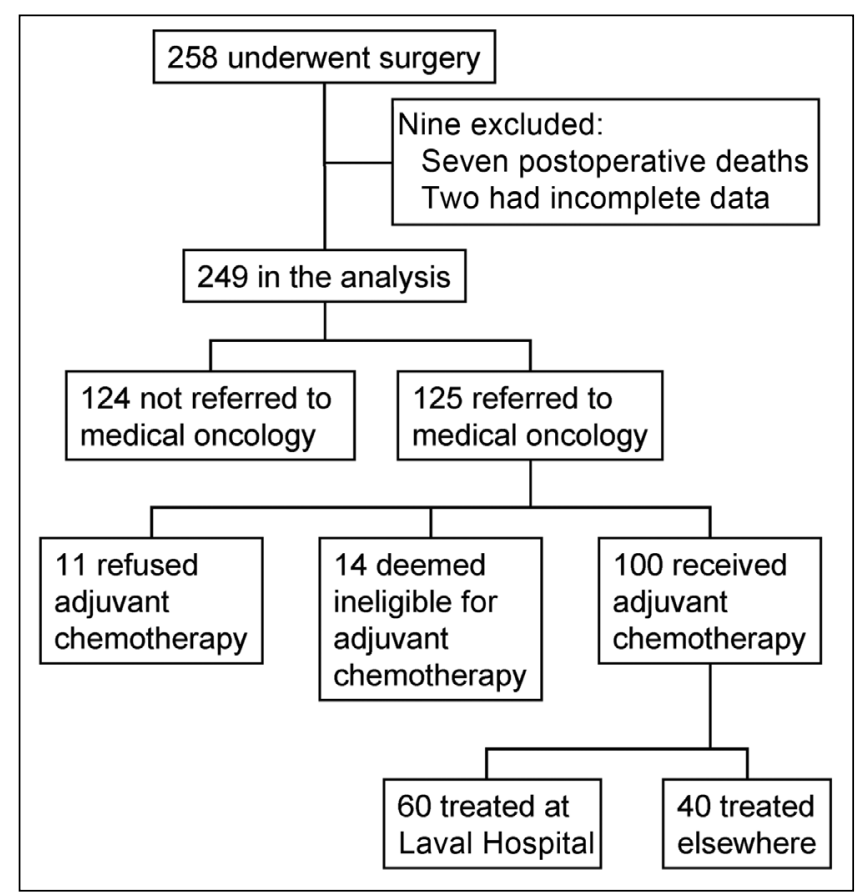

Figure 1) Flow of patients who underwent a surgical resection for lung cancer at Laval Hospital from March 2004 to January 2006

Finally, in case of hospitalization during the course of therapy, the cause of hospitalization was recorded.

\section{Statistics}

Descriptive statistics (proportions or means, medians and SDs when appropriate) were used to describe the study population. Logistic regression analysis was used to investigate whether reference to medical oncology depended on the surgeon who performed the surgery. Clinical characteristics of those who received adjuvant chemotherapy were compared with those who did not receive adjuvant chemotherapy using Fisher's exact tests for the categorical variables and unpaired $t$ tests for the continuous variables. Predictors of adjuvant chemotherapy were investigated using logistic regression analyses. The influence of each of the demographic and perioperative characteristics on the likelihood of receiving adjuvant chemotherapy was hence examined. In all the analyses, given the multitude of comparisons involved, statistical significance was set at the $\mathrm{P}<0.01$ level.

\section{RESULTS}

Patients and reference patterns to medical oncology A total of 258 patients underwent surgery (Figure 1). Seven patients were excluded because of early postoperative death and two patients were excluded because of incomplete data. Data from 249 patients (59\% male; mean [ \pm SD] age of $63 \pm 9$ years; $94 \%$ NSCLC; $21 \%$ stage IA; $28 \%$ stage IB; $3 \%$ stage IIA; $22 \%$ stage IIB; $12 \%$ stage IIIA; $15 \%$ stages IIIB and IV) were analyzed.

Of the 249 patients, 125 (50\%) were referred to medical oncology for consideration of adjuvant chemotherapy. The reasons for not referring to medical oncology were not clearly stated in most cases $(n=76 ; 61 \%)$. The reasons for not referring in the 48 other patients were as follows: complicated postoperative course $(n=15)$, comorbid disease contraindicating 
TABLE 1

A comparison of the patients who received adjuvant chemotherapy with those who did not

\begin{tabular}{|c|c|c|c|}
\hline & $\begin{array}{c}\text { Received } \\
\text { adjuvant } \\
\text { hemotherapy } \\
(n=100)\end{array}$ & $\begin{array}{l}\text { Did not receive } \\
\text { adjuvant } \\
\text { chemotherapy } \\
\quad(n=149)\end{array}$ & $\mathbf{P}$ \\
\hline Male sex, \% & 60 & 87 & 0.90 \\
\hline Age, years, mean $\pm S D$ & $61 \pm 8.6$ & $64 \pm 9.6$ & 0.005 \\
\hline \multicolumn{4}{|l|}{ Tumour stage, $\mathrm{n}$} \\
\hline IA & $5^{*}$ & 47 & \\
\hline IB & 24 & 45 & \\
\hline$\| A$ & 6 & 1 & \\
\hline IIB & 26 & 29 & \\
\hline IIIA & 18 & 11 & \\
\hline IIIB and IV & 21 & 16 & $<0.0001$ \\
\hline \multicolumn{4}{|l|}{ Histology, n } \\
\hline NSCLC & 87 & 147 & \\
\hline SCLC & 7 & 0 & \\
\hline Mixed (NSCLC plus SCLC) & 6 & 1 & \\
\hline Others & 0 & 1 & $<0.0001$ \\
\hline Current smokers, $\mathrm{n}$ & 40 & 62 & 0.90 \\
\hline \multicolumn{4}{|l|}{ Comorbidities, $n$} \\
\hline COPD & 40 & 76 & 0.10 \\
\hline Mild & 29 & 38 & \\
\hline Moderate (IIA) & 21 & 50 & \\
\hline Moderate (IIB) & 2 & 1 & \\
\hline Coronary artery disease, $\mathrm{n}$ & 14 & 31 & 0.18 \\
\hline Diabetes & 6 & 22 & 0.04 \\
\hline Chronic renal failure & 79 & 133 & 0.03 \\
\hline Other cancer & 11 & 25 & 0.27 \\
\hline Incomplete surgical resection, $\mathrm{n}$ & 9 & 12 & 0.82 \\
\hline \multicolumn{4}{|l|}{ Surgical procedure, $\mathrm{n}$} \\
\hline Pneumonectomy & 21 & 14 & \\
\hline Lobectomy & 68 & 111 & \\
\hline Bilobectomy & 11 & 24 & 0.03 \\
\hline \multicolumn{4}{|l|}{ Performance status (ECOG), $n$} \\
\hline 0 & 49 & 42 & \\
\hline 1 & 47 & 92 & \\
\hline 2 & 1 & 13 & \\
\hline Missing data & 3 & 2 & 0.0004 \\
\hline Length of stay, days, mean \pm SD & $9.3 \pm 5.4$ & $14.2 \pm 16.0$ & 0.0008 \\
\hline \multicolumn{4}{|l|}{ Surgeon, $\mathrm{n}$} \\
\hline A & 50 & 66 & \\
\hline B & 0 & 2 & \\
\hline $\mathrm{C}$ & 29 & 58 & \\
\hline $\mathrm{D}$ & 21 & 23 & 0.22 \\
\hline \multicolumn{4}{|l|}{ Date of surgery, $n$} \\
\hline March 1, 2004, to May 31, 2004 & 1 & 25 & \\
\hline June 1, 2004, to May 31, 2005 & 59 & 75 & \\
\hline June 1,2005 , to January 31,2006 & 0640 & 49 & $<0.0001$ \\
\hline
\end{tabular}

*Includes four patients with small-cell lung cancer (SCLC). COPD Chronic obstructive pulmonary disease; ECOG Eastern Cooperative Oncology Group; NSCLC Non-small-cell lung cancer

chemotherapy $(n=10)$, patient refusal $(n=9)$, surgeon's decision $(n=6)$; disease progression $(n=3)$, advanced age $(n=3)$, other cancer $(n=1)$ and period of time between surgery and reference
TABLE 2

Predictors of adjuvant chemotherapy in patients with resected lung cancer

\begin{tabular}{lcc}
\hline Predictors & OR & 95\% Cl \\
\hline Tumour stage & & - \\
Stage IA (referent) & 1.0 & 2.4 to 27.7 \\
Stage IB & 8.2 & 8.4 to 97.4 \\
Stage IIA and IIIA & 28.7 & 5.7 to 84.3 \\
Stage IIIB and IV & 21.9 & - \\
Performance status & & \\
ECOG 0 (referent) & 1.0 & 0.19 to 0.77 \\
ECOG 1 & 0.38 & 0.01 to 1.00 \\
ECOG 2 & 0.10 & - \\
Histology & & 2.3 to 165.5 \\
NSCLC (referent) & 1.00 & 0.89 to 0.98 \\
SCLC or mixed tumour & 19.4 & - \\
Length of stay, days & $0.93^{*}$ & \\
Date of surgery & & 2.3 to 163.1 \\
$\quad$ March 1, 2004, to May 31, 2004 & 1.0 & 1.6 to 116.5 \\
$\quad$ (referent) & & 0.91 to 0.98 \\
June 1, 2004, to May 31, 2005 & 19.5 & \\
June 1, 2005, to January 31, 2006 & 13.8 & $0.95^{*}$ \\
Age, years &
\end{tabular}

${ }^{*}$ For length of stay and age, the OR indicates that, for each one-day increment in length of stay or one-year increment in age, the probability of receiving adjuvant chemotherapy decreases by 7\% (1.00 to 0.93) and 5\% (1.00 to 0.95), respectively. ECOG Eastern Cooperative Oncology Group; NSCLC Non-small-cell lung cancer; SCLC Small-cell lung cancer

to medical oncology believed to be too long $(n=1)$. Reference to medical oncology was not related to the surgeon who performed the resection. Following the initial consultation in medical oncology, 14 patients were deemed ineligible for adjuvant chemotherapy because of tumour stage or comorbidities, and 11 refused to receive it.

Patients receiving adjuvant chemotherapy

One hundred patients finally received chemotherapy. Comparisons between those who received chemotherapy and those who did not are shown in Table 1 . The results of the regression analyses are shown in Table 2. Tumour stage and performance status were the most powerful predictors of adjuvant chemotherapy. Histological type, longer length of stay, date of surgery and older age were the other predictors. Of note, 29 of the 61 patients (48\%) with stage II lung cancer did not receive adjuvant chemotherapy.

Compliance and toxicity

Sixty patients received adjuvant chemotherapy at Laval Hospital, and contributed to the toxicity and compliance analyses. The 40 remaining patients were transferred to their community hospital where they received adjuvant chemotherapy after the indication was ascertained at Laval Hospital. Treatment was initiated 47 days (median) after surgery (Figure 2).

Chemotherapy mainly consisted of cisplatin-vinorelbine $(\mathrm{n}=23 ; 38 \%)$, cisplatin-etoposide $(\mathrm{n}=13 ; 22 \%)$ and carboplatinpaclitaxel $(n=12 ; 20 \%)$ (Table 3$)$. Sixty-six per cent of patients completed all four scheduled cycles. There was no treatment-related death. Complete data on toxicity were available for 48 patients. Table 4 gives the proportion of patients 


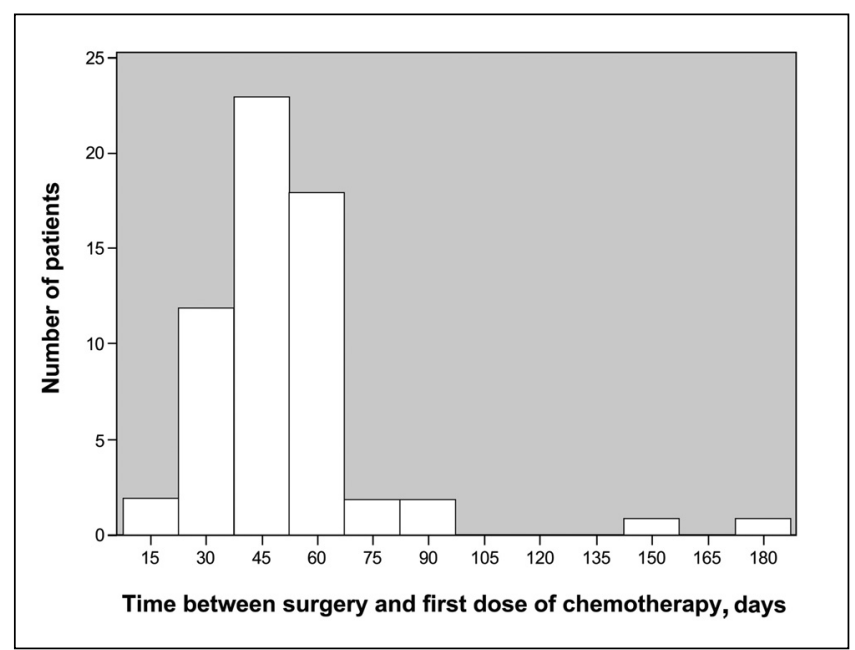

Figure 2) Number of patients according to the number of days between surgery and initiation of adjuvant chemotherapy

who experienced grade 3 or 4 toxicity with vinorelbine and cisplatin, and with any other chemotherapy regimen. Overall, grade 3 or 4 toxicity consisted mainly of cytopenia (40\%) and fatigue (23\%). Seven patients (15\%) had to be hospitalized because of side effects, including three for febrile neutropenia.

\section{DISCUSSION}

We report the results of a retrospective analysis conducted in a university-affiliated hospital regarding the prescription of adjuvant chemotherapy in resected lung cancer patients. Although compliance was high and toxicity was acceptable, we found that one-half of those who were submitted to lung resection for lung cancer did not receive adjuvant chemotherapy. Poor performance status, increasing age and increasing hospital length of stay at the time of surgical resection decreased the probability of adjuvant chemotherapy. There appeared to be no bias with the referring surgeon.

Kassam et al (10) have reported the results of a similar analysis that was limited to the patterns of reference to medical oncology for consideration of adjuvant chemotherapy in completely resected NSCLC. They found that from May 2003 to May 2004, only 31\% (36 of 115) of patients were referred for adjuvant therapy. During the subsequent year, 63\% (56 of 89) of patients were referred. Of 92 patients referred to medical oncology, only 42 (46\%) received adjuvant chemotherapy. The main reason for not prescribing treatment was patient refusal $(50 \%)$. Our study found a $50 \%$ rate of being referred to medical oncology. Eighty per cent of these patients received therapy and only $9 \%$ refused it.

The most obvious limitation of our study is that the data were obtained retrospectively, with limited information on those who received chemotherapy in community hospitals. In the reference analysis, we nevertheless considered every consecutive patient who had undergone resection for lung cancer. Our results are similar to those observed by Kassam et al (10), despite different methodologies. Our data were mainly collected after the ASCO meeting in May 2004, when medical evidence favouring adjuvant chemotherapy was released, and included a small number of patients with SCLC who all received, with one exception, adjuvant chemotherapy. In addition, we considered
TABLE 3

Prescriptions of chemotherapy according to histological types $(n=60)$

\begin{tabular}{lccc}
\hline Prescription & NSCLC, $\mathbf{n}$ & SCLC, $\mathbf{n}$ & Mixed tumour, $\mathbf{n}$ \\
\hline Cisplatin-vinorelbine & 23 & 0 & 0 \\
Carboplatin-paclitaxel & 12 & 0 & 0 \\
Cisplatin-etoposide & 3 & 7 & 3 \\
Cisplatin-gemcitabine & 8 & 0 & 0 \\
Carboplatin-gemcitabine & 2 & 0 & 0 \\
Carboplatine-vinorelbine & 1 & 0 & 0 \\
Carboplatin-etoposide & 0 & 0 & 1 \\
\hline
\end{tabular}

NSCLC Non-small-cell lung cancer; SCLC Small-cell lung cancer

TABLE 4

Drug-related adverse events: Proportion of patients with grade 3 or $\mathbf{4}$ toxicity at any point in time during adjuvant chemotherapy

\begin{tabular}{lcc}
\hline Adverse event & $\begin{array}{c}\text { Cisplatin-vinorelbine, } \\
(\mathbf{n}=\mathbf{1 5})\end{array}$ & $\begin{array}{c}\text { Any other regimen, } \mathbf{n} \\
(\mathbf{n}=\mathbf{3 3})\end{array}$ \\
\hline Fatigue & 4 & 7 \\
Alopecia* & $2^{*}$ & $16^{*}$ \\
Cytopenia & 11 & 8 \\
Nausea & 3 & 1 \\
Vomiting & 1 & 1 \\
Diarrhea & 0 & 3 \\
Constipation & 1 & 2 \\
Dysphagie & 1 & 0 \\
Mucositis or stomatitis & 0 & 0 \\
Dysgeusia* & $1^{*}$ & $4^{*}$ \\
Peripheral neuropathy & 0 & 1 \\
Tinnitus & 0 & 1
\end{tabular}

*Number of patients with grade 2 toxicity (the maximum score for these items)

patients with incomplete resection, a situation in which the benefits of adjuvant therapy are unclear (11).

The eligibility criteria in the International Adjuvant Lung Cancer (IALT) trial specified that patients had to be randomly assigned to treatment group or control group within sixty days after surgery (12). Similarly, one inclusion criterion from the NCIC BR.10 trial (6) and from the ANITA trial (13) was that chemotherapy had to be commenced within six weeks of surgery. Our study showed that treatment was initiated 47 days (median) after surgery. Good collaboration is necessary among surgeons, pathologists and oncologists to be able to initiate treatment within a reasonable delay. Whether any delay would decrease the benefit of adjuvant chemotherapy remains unknown but is likely.

Regarding compliance to chemotherapy, only 50\% of patients received the predicted four cycles of chemotherapy in the ANITA (13) and NCIC BR.10 trials (6). We observed a $66 \%$ full-compliance rate. The differences may be related to our inclusion of patients with SCLC. Nevertheless, our results confirm the application of adjuvant chemotherapy in day-today practice. In the NCIC BR.10 trial, hospitalization was required in $19 \%$ of patients for medical problems related to toxicity (6). These data were not available for the other two trials $(12,13)$. We found that $15 \%$ were hospitalized because of side effects. 


\section{CONCLUSION}

Adjuvant chemotherapy is gaining acceptance in clinical practice. Although one-half of those who were submitted to lung resection for lung cancer did not receive adjuvant chemotherapy, the results of the present study confirm the feasibility of adjuvant chemotherapy in routine care of patients with lung cancer. Toxicity to adjuvant chemotherapy was similar to that observed in published clinical trials. More patients, especially those with stages II and IIIA NSCLC, should be referred to medical oncology for consideration of adjuvant chemotherapy. Further study should focus on the factors associated with reference to medical oncology.

SUPPORT: This study originated from Laval Hospital and was supported by local funds.

\section{REFERENCES}

1. Parkin DM. Global cancer statistics in the year 2000. Lancet Oncol 2001;2:533-43. (Erratum in 2001;2:596).

2. Spiro SG, Porter JC. Lung cancer - where are we today? Current advances in staging and nonsurgical treatment. Am J Respir Crit Care Med 2002;166:1166-96.

3. Mountain CF. Revisions in the International System for Staging Lung Cancer. Chest 1997;111:1710-7.

4. Spira A, Ettinger DS. Multidisciplinary management of lung cancer. N Engl J Med 2004;350:379-92.
5. Pignon JP, Tribodet H, Scagliotti GV, et al. Lung Adjuvant Cisplatin Evaluation (LACE): A pooled analysis of five randomized clinical trials including 4,584 patients. J Clin Oncol 2006;24(Suppl 18):7008. (Abst)

6. Winton T, Livingston R, Johnson D, et al. Vinorelbine plus cisplatin vs. observation in resected non-small-cell lung cancer. N Engl J Med 2005;352:2589-97.

7. Simon GR, Turrisi A. Management of small cell lung cancer: ACCP evidence-based clinical practice guidelines (2nd edition). Chest 2007;132(3 Suppl):324S-339S.

8. Global Initiative for Chronic Obstructive Lung Disease (GOLD). Global Strategy for Diagnosis, Management, and Prevention of COPD. $<$ http://www.goldcopd.com> (Version current at May 28, 2008).

9. Oken MM, Creech RH, Tormey DC, et al. Toxicity and response criteria of the Eastern Cooperative Oncology Group. Am J Clin Oncol 1982;5:649-55.

10. Kassam F, Shepherd FA, Johnston M, et al. Referral patterns for adjuvant chemotherapy in patients with completely resected nonsmall cell lung cancer. J Thorac Oncol 2007;2:39-43.

11. Lacasse Y, Bucher HC, Wong E, et al. "Incomplete resection" in non-small cell lung cancer: Need for a new definition. Canadian Lung Oncology Group. Ann Thorac Surg 1998;65:220-6.

12. Arriagada R, Bergman B, Dunant A, Le Chevalier T, Pignon JP, Vansteenkiste J. Cisplatin-based adjuvant chemotherapy in patients with completely resected non-small-cell lung cancer. N Engl J Med 2004;350:351-60.

13. Douillard JY, Rosell R, De Lena M, et al. Adjuvant vinorelbine plus cisplatin versus observation in patients with completely resected stage IB-IIIA non-small-cell lung cancer (Adjuvant Navelbine International Trialist Association [ANITA]): A randomised controlled trial. Lancet Oncol 2006; 7: 719-727. (Erratum in 2006;7:797). 


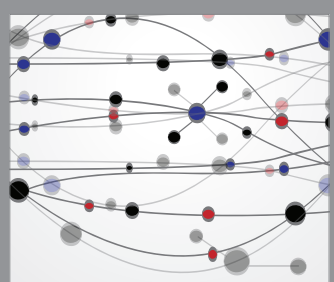

The Scientific World Journal
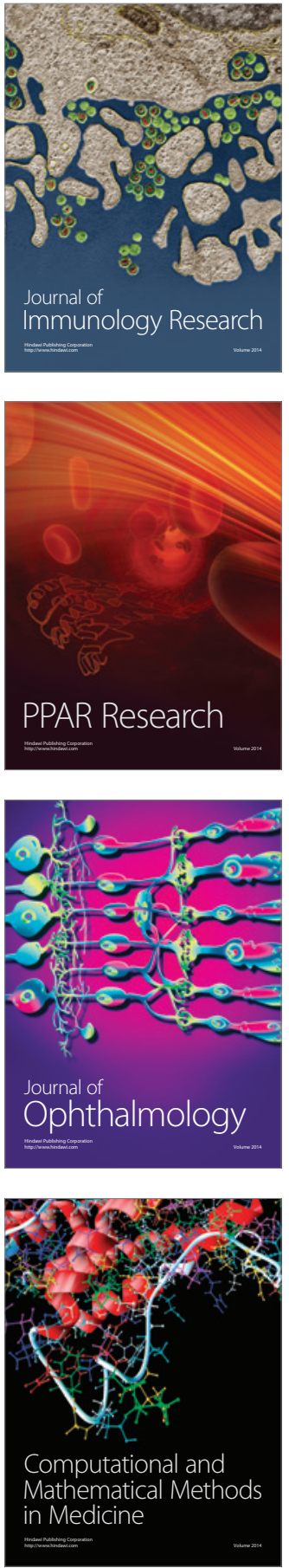

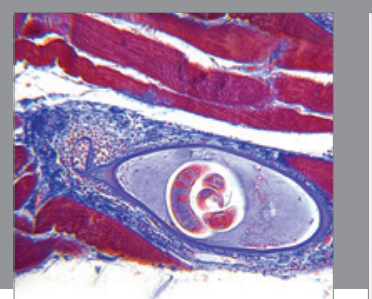

Gastroenterology Research and Practice

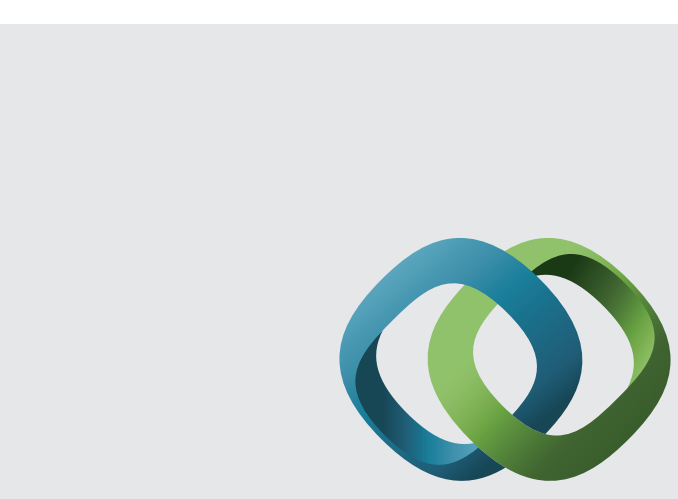

\section{Hindawi}

Submit your manuscripts at

http://www.hindawi.com
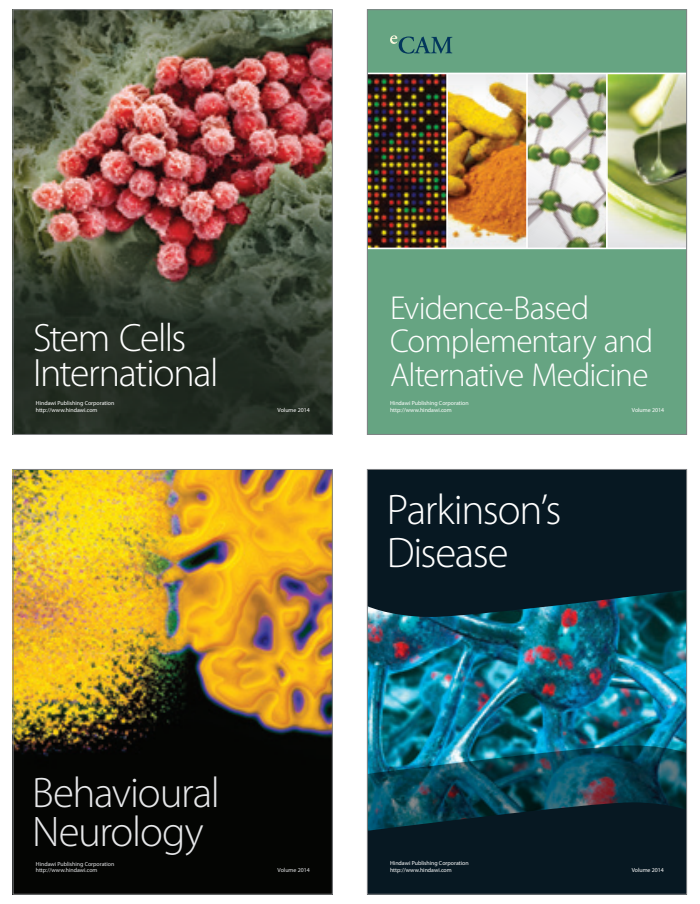
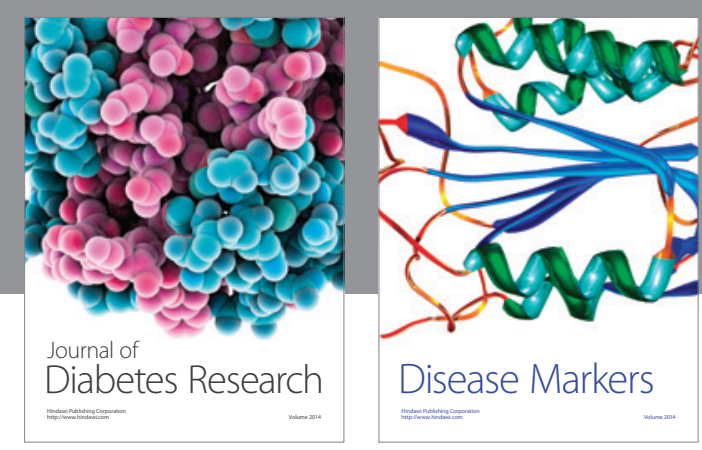

Disease Markers
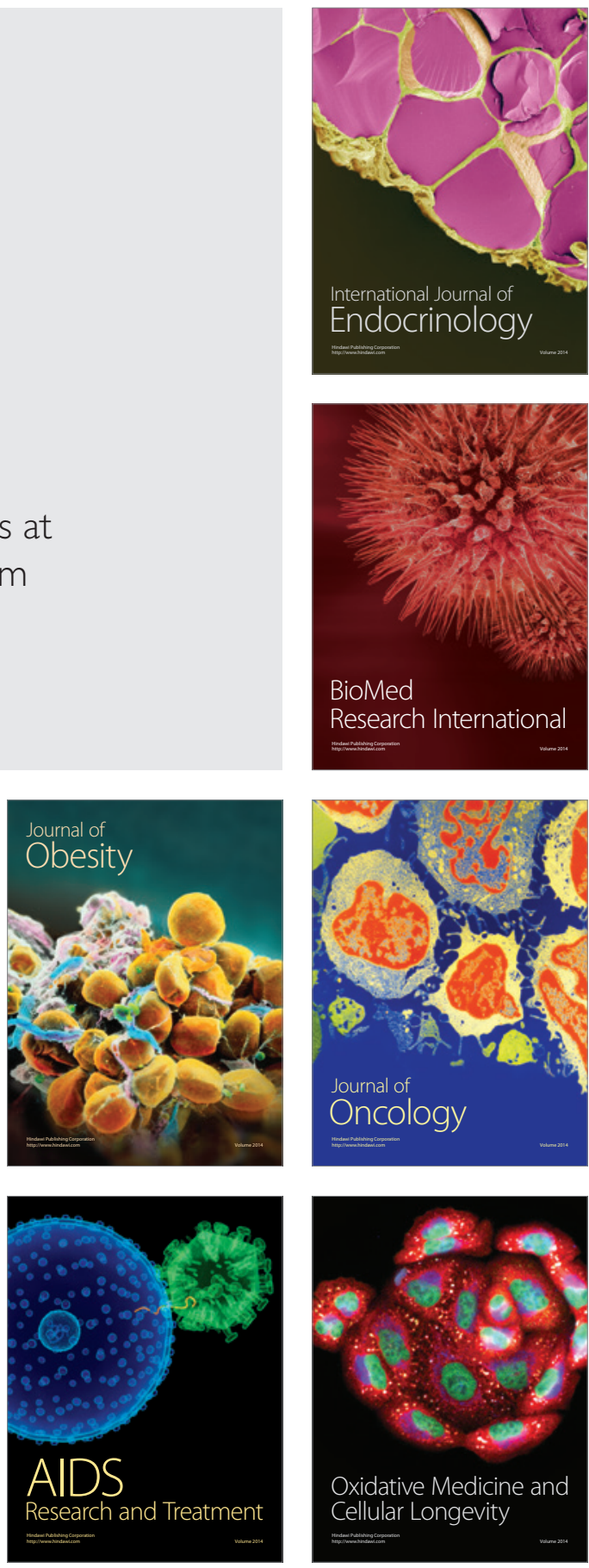